\title{
Toxicity assessment of fosthiazate, metalaxyl-M and imidacloprid and their interaction with copper on Daphnia magna
}

\author{
A. Kungolos ${ }^{1}$, V. Tsiridis ${ }^{1}$, H. Nassopoulos ${ }^{2}$, P. Samaras ${ }^{3}$ \\ $\&$ N. Tsiropoulos ${ }^{4}$ \\ ${ }^{1}$ Department of Planning and Regional Development, \\ University of Thessaly, Volos, Greece \\ ${ }^{2}$ Department of Civil Engineering, University of Thessaly, Volos, Greece \\ ${ }^{3}$ Department of Pollution Control Technologies, \\ Technological Educational Institute of West Macedonia, Kozani, Greece \\ ${ }^{4}$ Department of Agriculture, Crop Production and Rural Environment, \\ University of Thessaly, Nea Ionia-Volos, Greece
}

\begin{abstract}
The toxic effects of three agrochemicals (fosthiazate, metalaxyl-M and imidacloprid) and copper were investigated in this study on the crustacean Daphnia magna. Copper was the most toxic tested compound with the lowest $\mathrm{EC}_{50}$ value, equal to $0.11 \mathrm{mg} / \mathrm{L}$. Among the three agrochemicals, fosthiazate was the most toxic with an $\mathrm{EC}_{50}$ value equal to $0.32 \mathrm{mg} / \mathrm{L}$, about two orders of magnitude lower than the $\mathrm{EC}_{50}$ of metalaxyl-M and imidachloprid. The interactive effects of binary mixtures of fosthiazate, metalaxyl-M or imidacloprid and copper were also investigated. The interactive effects between agrochemicals and copper were antagonistic in most cases, while additive effects were observed for binary mixtures of metalaxyl-M and copper for low concentration combinations.
\end{abstract}

Keywords: pesticides, agrochemicals, bioassays, Daphnia magna, interactive effects. 


\section{Introduction}

The contamination of the aquatic and terrestrial environment with various agrochemicals poses a direct risk of toxic effects on the ecosystem. An integrated evaluation of the environmental impact of agrochemicals requires performance of both physicochemical and ecotoxicological analyses. Ecotoxicological analysis is an important issue for the assessment of chemical contamination and its potential impact on water quality and biota of receiving aquatic ecosystems [1]. Bioassays provide a more direct measure of environmentally relevant toxicity of contaminated systems than chemical analyses, since aquatic and terrestrial ecosystems are impacted by numerous chemicals. In addition, single chemicals almost never occur alone in nature; even with products or wastes containing only a few chemicals, the ultimate toxicity is not the sum of the individual toxicities. Phenomena such as e.g. bioavailability, synergistic or antagonistic effects indeed always dictate the ultimate hazard of the mixtures [1-3].

Each year during the last five decades an enormous amount of pesticides has been used in agricultural activities. The environmental effect of this use is that the pesticides can be found in important concentrations in surface waters and ground waters because of their physicochemical properties such as Log octanol/ water partition coefficient, hydrolysis, photolysis, adsorption/desorption, mobility, volatility $[4,5]$. These concentrations can have an adverse effect on aquatic organisms. Furthermore, pesticides are never observed in aquatic environment alone. Various pesticides that are used in agriculture can be found together in various concentrations in water close to agricultural fields [5]. The existence in the same time of different pesticides may have an additive, antagonistic or synergistic effect on the aquatic life [2].

The objective of this study is the evaluation of the toxic effects of three pesticides (fosthiazate, metalaxyl-M and imidacloprid) alone or in combination with copper on the crustacean D. magna.

\section{Materials and methods}

The toxicity tests on $D$. magna were carried out using a commercial toxicity test Daphtoxkit F magna [6] provided by Microbiotest Inc., Belgium. Experiments with Daphtoxkit F are based on the immobilization of the crustacean D. magna due to the action of toxicants. D. magna were hatched from dormant eggs (ephippia) in 3 days under continuous illumination (6000 lux) at $20^{\circ} \mathrm{C}$. Neonates (younger than $24 \mathrm{~h}$ ) were exposed to the samples for $24 \mathrm{~h}$ at a temperature of $20^{\circ} \mathrm{C}$ in darkness. Twenty neonates were used for each concentration or combination of concentrations examined in a series of 4 well; each well containing $10 \mathrm{~mL}$ toxicant solution and 5 neonates. The agrochemicals examined for their toxic properties were: fosthiazate, metalaxyl-M and imidacloprid using their commercial formulations of Nemathorin, Ridomil and Confidor, respectively. The toxicity of copper was also evaluated using copper chloride dehydrate, $\left(\mathrm{CuCl}_{2} \cdot 2 \mathrm{H}_{2} \mathrm{O}\right)$ provided by J.T. Baker, Holland. The toxicities of the 
tested compounds were evaluated by preparing certain dilution of each compound for the estimation of the $\mathrm{EC}_{50}$ values. The effective concentrations $\left(\mathrm{EC}_{50}\right.$ values) causing $50 \%$ immobilization to $D$. magna was calculated according to Probit model [7].

The interactive toxic effects between agrochemicals and copper on D. magna were also investigated and the evaluation of the results was performed by statistical analysis. The concentrations of the tested compounds used, were obtained from the $\mathrm{EC}_{50}$ estimation experiments of each compound.

A mathematical model was used for the prediction of the expected effect of the combined mixtures $[2,3]$. According to this model, if $P_{1}$ is the inhibition rate caused by a certain concentration of chemical $A_{1}$ and $P_{2}$ the inhibition rate caused by a certain concentration of chemical $\mathrm{A}_{2}$, then, the theoretically expected additive inhibition rate $\mathrm{P}(\mathrm{E})$, when the same concentrations of the two chemicals are applied together, is given by the Equation:

$$
\mathrm{P}(\mathrm{E})=\mathrm{P}_{1}+\mathrm{P}_{2}-\mathrm{P}_{1} \mathrm{P}_{2} / 100
$$

With regard to the significance of the differences between theoretically predicted and observed experimental values, one sample hypothesis for testing percentages was used for the D. magna test [8]. The null hypotheses were that the observed values were higher or lower than the theoretically predicted ones, for synergistic and antagonistic effects respectively. The result was considered to be antagonistic or synergistic, only if the observed effect was significantly lower or higher respectively than the theoretically predicted one at the 0.05 level of significance.

\section{Results and discussion}

The toxicities of the single agrochemicals and copper were first examined by applying several dilutions for each one of them and the $\mathrm{EC}_{50}$ value was evaluated as an endpoint. The $\mathrm{EC}_{50}$ values and the corresponding confidence ranges calculated using Probit model for the tested compounds are presented in Table 1, while the dose/response curves are given in Figure 1.

Table 1: $\mathrm{EC}_{50}$ values and the corresponding confidence ranges for the tested compounds on D. magna.

\begin{tabular}{lcc}
\hline \multicolumn{1}{c}{ Compound } & $\mathbf{E C}_{\mathbf{5 0}}(\mathbf{m g} / \mathbf{L})$ & Confidence range $(\mathbf{m g} / \mathbf{L})$ \\
\hline Fosthiazate (Nemathorin) & 0.32 & $0.25-0.41$ \\
Metalaxyl-M (Ridomil) & 27.6 & $21.1-38.0$ \\
Imidacloprid (Confidor) & 64.6 & $43.3-122.5$ \\
Copper $\left(\mathrm{CuCl}_{2} \mathrm{H}_{2} \mathrm{O}\right)$ & 0.11 & $0.09-0.13$ \\
\hline
\end{tabular}


As it is shown in Table 1, copper was the most toxic tested compound with the lowest $\mathrm{EC}_{50}$ value, equal to $0.11 \mathrm{mg} / \mathrm{L}$. Among the three agrochemicals, fosthiazate was the most toxic with an $\mathrm{EC}_{50}$ value equal to $0.32 \mathrm{mg} / \mathrm{L}$, about two orders of magnitude lower than the $\mathrm{EC}_{50}$ of metalaxyl-M and imidachloprid. The toxicity of the three agrochemicals to D. magna was in the order: fosthiazate> metalaxyl-M> imidacloprid.

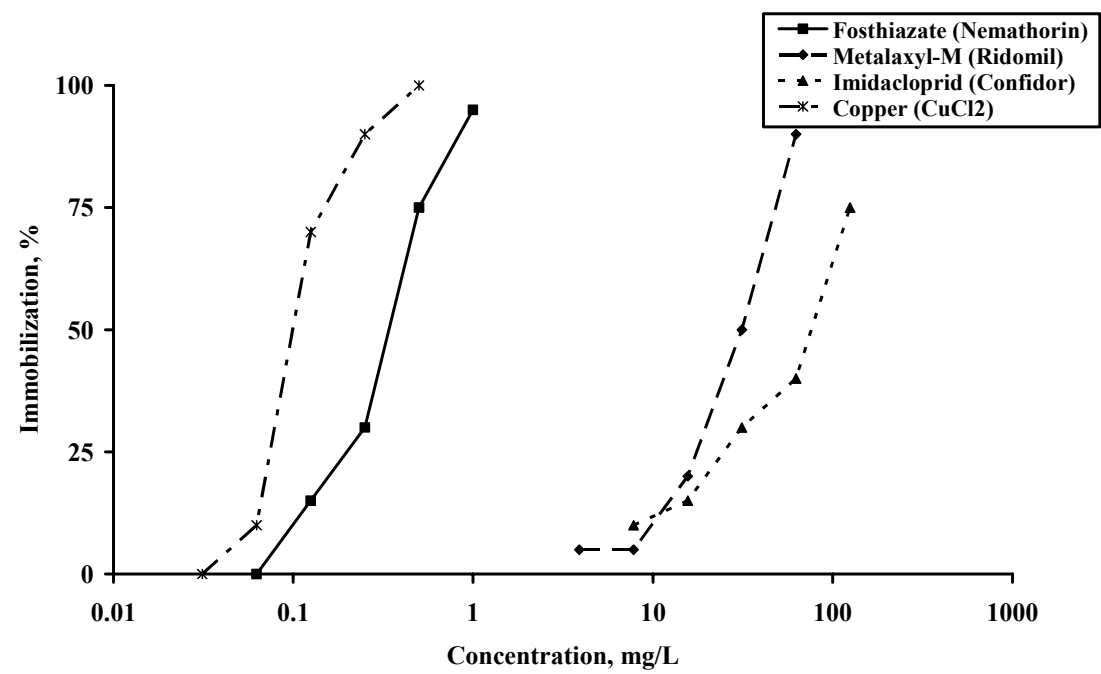

Figure 1: D. magna immobilization caused by the tested concentration of agrochemicals and copper (dose/response curves).

After having tested the effects of the compounds alone on Daphnia magna, the interactive effect between the agrochemicals and copper was evaluated. The theoretical expected interactive effects, as calculated by Equation 1 and the observed effects for the combine action of fosthiazate and copper are illustrated in Figure 2. It can be seen that in most cases the observed effect was lower than the theoretical expected, indicating their antagonistic action. The theoretically expected and observed effects for the combined action of metalaxyl-M and copper on D. magna are shown in Figure 3. The mode of interaction was generally antagonistic with few cases of additive action for the low concentration combinations A, B and C (Figure 3). The theoretical expected and observed effects for the combined action of imidacloprid and copper are presented in Figure 4. The interactive effects for these binary mixtures were antagonistic for all concentration combinations. 


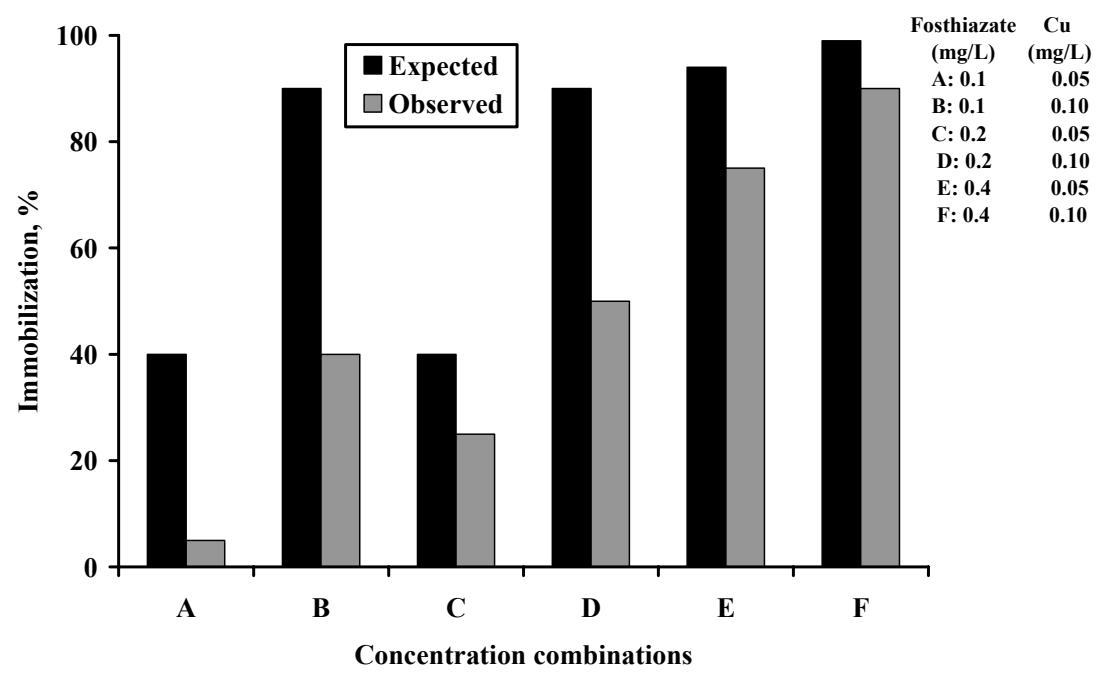

Figure 2: Comparison between theoretically expected and observed immobilization for the combined effect of fosthiazate and copper on D. magna.

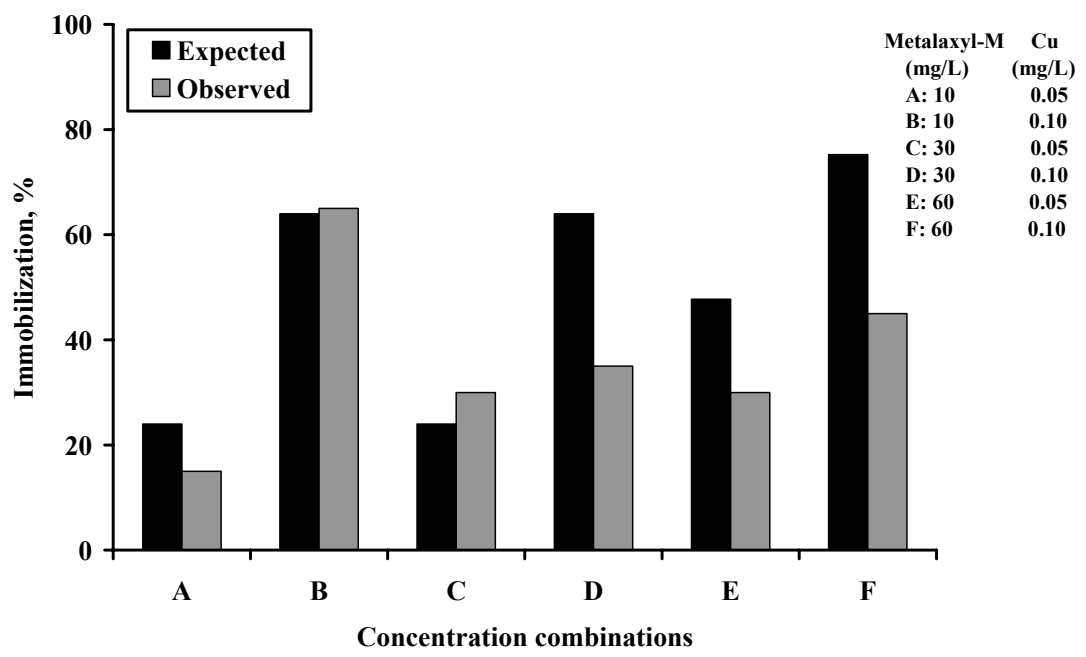

Figure 3: Comparison between theoretically expected and observed immobilization for the combined effect of metalaxyl-M and copper on D. magna. 


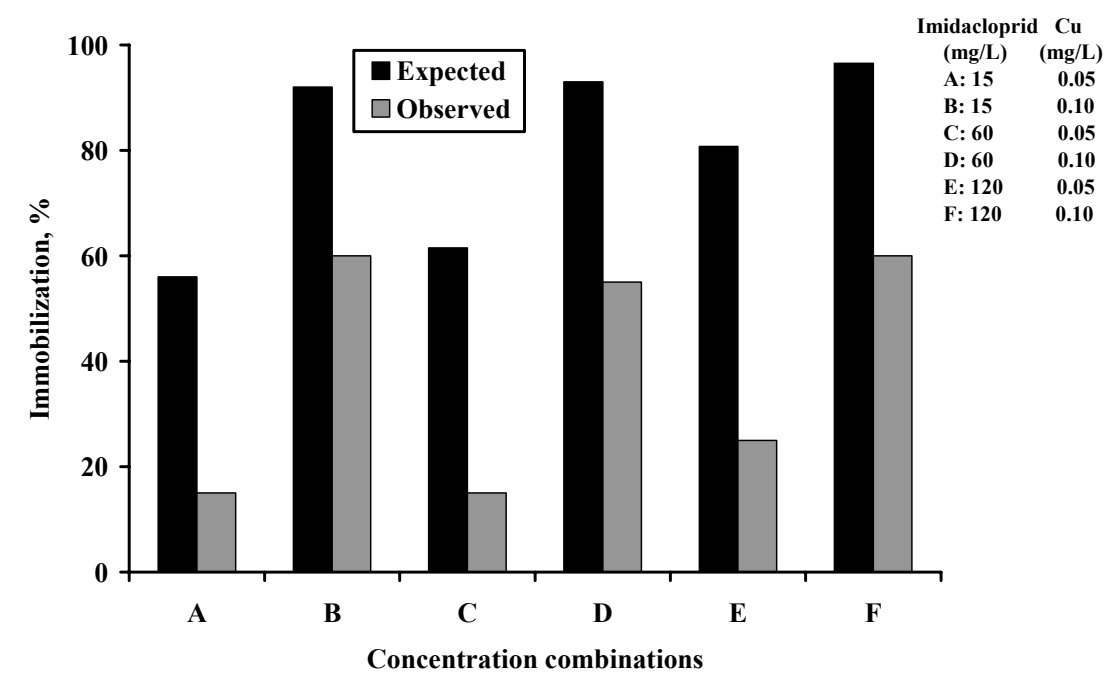

Figure 4: Comparison between theoretically expected and observed immobilization for the combined effect of Imidacloprid and copper on D. magna.

\section{Conclusions}

The crustacean D. magna was used in this study in order to examine the effect of three agrochemicals, single and in combination with copper. Fosthiazate was the most toxic agrochemical. The interactive effect between fosthiazate or imidacloprid and copper was antagonistic for all tested concentration combinations. The results of the interactive effect between metalaxyl-M and copper were generally either synergistic or additive, depending on the concentration combinations. Little is known about the mechanisms that make the interactive effects of toxicants additive, synergistic or antagonistic. The results of this study showed that the combination of the tested agrochemicals with copper may result to a toxicity reduction, due to antagonistic actions.

\section{References}

[1] Persoone G., Goyvaerts M., Janssen C., De Coen W. and Vangheluwe M., Cost-effective acute hazard monitoring of polluted waters and waste dumps with the aid of Toxkits. Final Report, Commission of the European Communities, Contract ACE 89/BE 2/D3, 1993.

[2] Kungolos A., Samaras P., Kipopoulou A.M., Zoumboulis A. and Sakellaropoulos G.P., Interactive toxic effects of agrochemicals on aquatic organisms' Water Science and Technology, 40 (1), 357-364, 1999.

[3] Hadjispyrou S., Kungolos A. and Anagnostopoulos A., Toxicity, bioaccumulation and interactive effects of organotin, cadmium and 
chromium on Artemia franciscana. Ecotoxicology and Environmental Safety, 49, 179-186, 2001.

[4] Tsiropoulos N.G., Bakeas E.B., Raptis V. and Batista S.S., Evaluation of solid sorbents for the determination of fenhexamid, metalaxyl-M, pyrimethanil, malathion and myclobutanil residues in air samples Application to monitoring malathion and fenhexamid dissipation in greenhouse air using C-18 or Supelpak-2 for sampling. Analytica Chimica Acta , in press, 2006.

[5] Konstantinou I.K., Hela D.G., and Albanis T.A., The status of pesticide pollution in surface waters (rivers and lakes) of Greece. Part I. Review on occurrence and levels. Environmental Pollution, 141, 555-570, 2006.

[6] Daphtoxkit F magna, Crustacean toxicity screening test for freshwater, Standard Operational Procedure, Creasel, Deinze, Belgium, 16 pages, 1996.

[7] EPA, Methods for measuring the acute toxicity of effluents and receiving waters to freshwater and marine organisms. US Environmental Protection Agency, EPA/600/4-90/027F, Fourth Edition, 1993.

[8] Sanders D.H., Eng R.J. and Murph A.F., Statistics, a fresh approach. McGraw-Hill Company, New York, 1985. 